\title{
Thermodynamically equivalent distillation schemes to the Petlyuk column for ternary mixtures
}

\author{
Salvador Hernández ${ }^{\mathrm{a}, *}$, Juan Gabriel Segovia-Hernández ${ }^{\mathrm{a}}$, Vicente Rico-Ramírez ${ }^{\mathrm{b}}$ \\ ${ }^{a}$ Universidad de Guanajuato, Facultad de Química, Noria Alta s/n, Guanajuato, Gto. 36050, México \\ bInstituto Tecnológico de Celaya, Departamento de Ingeniería Química, Av. Tecnológico y García Cubas s/n, Celaya, Gto. 38010, México
}

Received 29 September 2003

\begin{abstract}
Thermally coupled distillation sequences for ternary separations have been shown to provide significant energy savings with respect to the conventional direct and indirect distillation sequences. Although the Petlyuk column is generally more efficient than the other thermally coupled schemes, its structure creates potential operating problems because of the bidirectional vapour interconnecting streams. In this paper, second law calculations were performed for the Petlyuk column and six alternative distillation schemes that show unidirectional flows; in principle, such alternative configurations are expected to present better operational properties than those of the original Petlyuk column. The results indicate that the proposed distillation arrangements have values of thermodynamic efficiency very close to that of the Petlyuk column. This result is important because let us establish that the alternative distillation sequences: (i) are thermodynamically equivalent to the Petlyuk column, (ii) could be more easily implemented in practice, and (iii) also achieve significant energy savings. (C) 2005 Published by Elsevier Ltd.
\end{abstract}

Keywords: Petlyuk column; Energy savings; Thermodynamic efficiency

\section{Introduction}

It is known that distillation is used for the separation of about $95 \%$ of all fluid separations in the chemical industry, and that around 3\% of the total energy consumption in the world is used in distillation units [1]. Motivated by the large demand of energy in distillation processes, researchers have developed new arrangements that can amass savings in both energy and capital costs [2]. As a result, new distillation sequences are emerging in order to reduce or improve the use of energy [3-5]. One method used to reduce the demands of energy in distillation sequences is the thermally coupled distillation sequences (TCDS), which can have energy savings of up to $30 \%$ in contrast to the conventional direct and indirect distillation sequences for the separation of ternary mixtures (A, B, C). In the case of ternary mixtures, there are two conventional distillation sequences, which are shown in Fig. 1. For the same separation, there are three TCDS schemes commonly used (see Fig. 2). The energy savings predicted in the TCDS schemes are achieved because of the

${ }^{*}$ Corresponding author. Fax: $+524737320006 \times 8108$.

E-mail address: hernasa@quijote.ugto.mx (S. Hernández). 


\section{Nomenclature}

$\begin{array}{ll}\text { ABC } & \text { ternary mixture } \\ \text { AB } & \text { binary mixture } \\ b & \text { exergy } \\ \text { BC } & \text { binary mixture } \\ \text { C1 } & \text { distillation column 1 } \\ \text { C2 } & \text { distillation column 2 } \\ \text { F11 } & \text { interconnecting liquid stream 1 } \\ \text { F12 } & \text { interconnecting liquid stream 2 } \\ \text { Fv1 } & \text { interconnecting vapour stream 1 } \\ \text { Fv2 } & \text { interconnecting vapour stream 2 } \\ h & \text { molar enthalpy } \\ \text { LW } & \text { lost work } \\ n & \text { mole flow }\end{array}$

PU-L Petlyuk column with unidirectional flows of liquid

PU-V Petlyuk column with unidirectional flows of vapour

RL Petlyuk column with reduction in the number of interconnecting liquid streams

RV Petlyuk column with reduction in the number of interconnecting vapour streams

RL-U PU-L scheme with reduction in the number of interconnecting liquid streams

RV-U PU-V scheme with reduction in the number of interconnecting vapour streams

$Q \quad$ heat

$S \quad$ molar entropy

$T_{0} \quad$ temperature of the surroundings

$T_{\mathrm{S}} \quad$ temperature of the system

$W_{\text {min }}$ minimum work for the separation

$W_{\mathrm{S}} \quad$ shaft work

$\eta \quad$ second law efficiency

reduction or elimination of remixing presented in conventional distillation sequences. Remixing occurs in conventional distillation sequences and it is associated with higher energy requirements; for example, for the conventional direct distillation sequence (Fig. 1a), the concentration of the intermediate component B in the first column reaches a maximum below the feed stage and then decreases in the bottoms of the column (Fig. 3). Such an effect is known as remixing and causes larger demands of energy because, in order to re-purify the

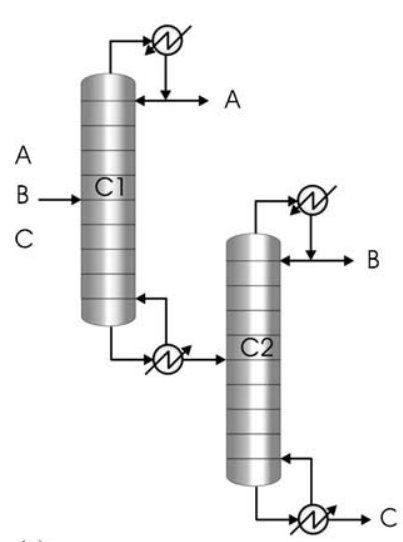

(a)

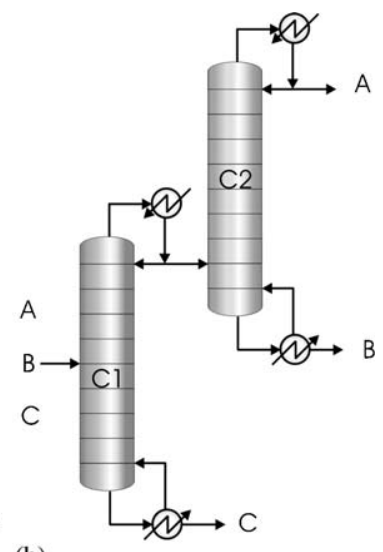

(b)

$$
\text { Indirect. }
$$

Fig. 1. Conventional distillation sequences for the separation of ternary mixtures. 

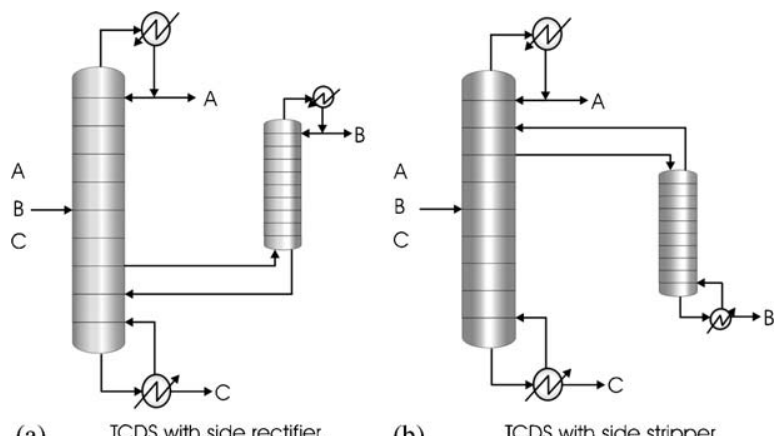

(a)

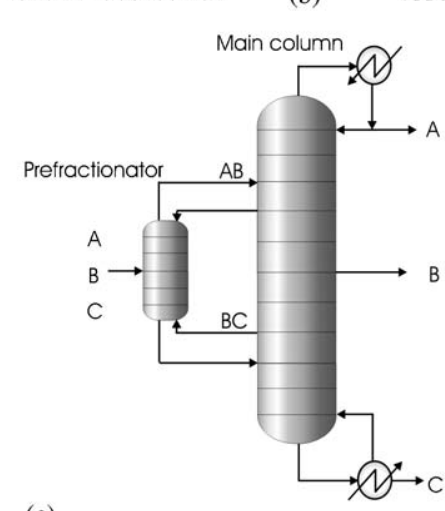

(c)

Petlyuk column

Fig. 2. TCDS for the separation of ternary mixtures.

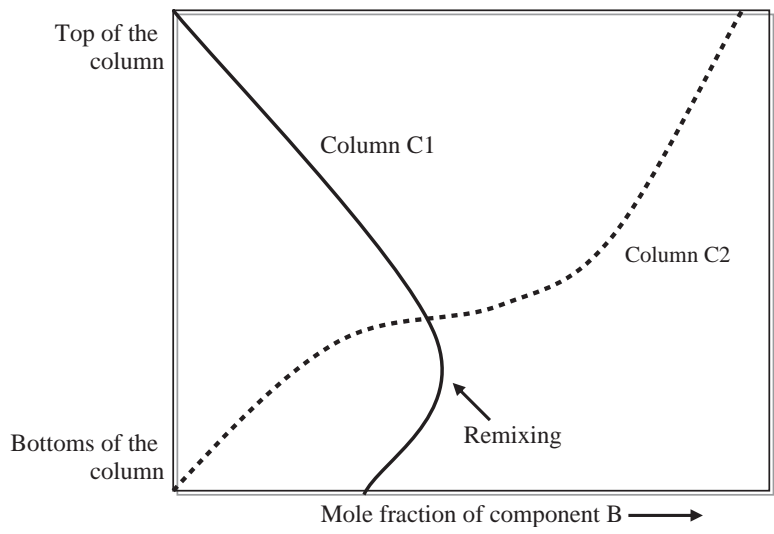

Fig. 3. Remixing in the conventional direct distillation sequence.

binary mixture $\mathrm{BC}$ in the second column, more energy will be required in the conventional distillation sequence. This remixing can be interpreted as a thermodynamic inefficiency in the use of the energy. In the TCDS sequences, the recycle streams are capable of significantly reducing remixing and the energy consumption required for ternary separations, as reported in the work of Hernandez et al. [6].

From the three TCDS shown in Fig. 2, the most energy efficient scheme is the Petlyuk column (fully thermally coupled distillation column), which can achieve energy savings of up to $50 \%$ in contrast to the conventional distillation sequences [7]. Recently, Agrawal and Fidkowski [8,9] reported alternative TCDS and show that those schemes can have better operational properties in comparison to the Petlyuk column. The main problem detected in the Petlyuk column is concerned with the two directions of flow in the interconnecting vapour streams. According to Fig. 2c, the vapour stream AB that leaves the top of the 


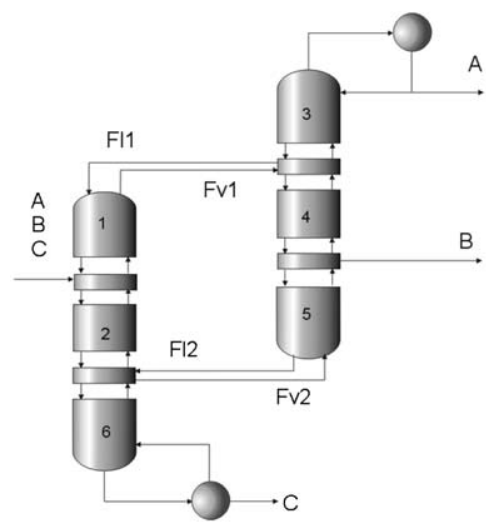

(a)

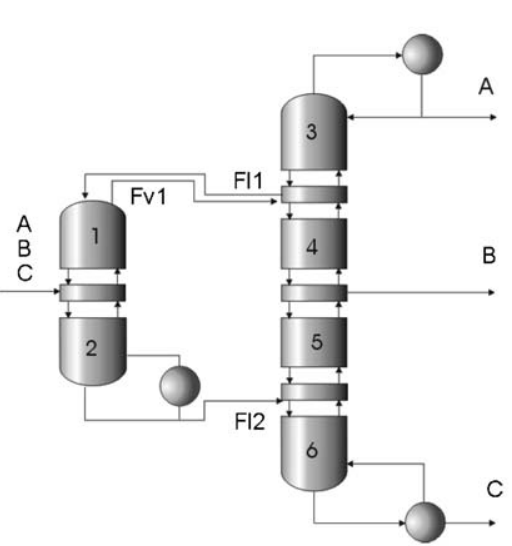

(d)

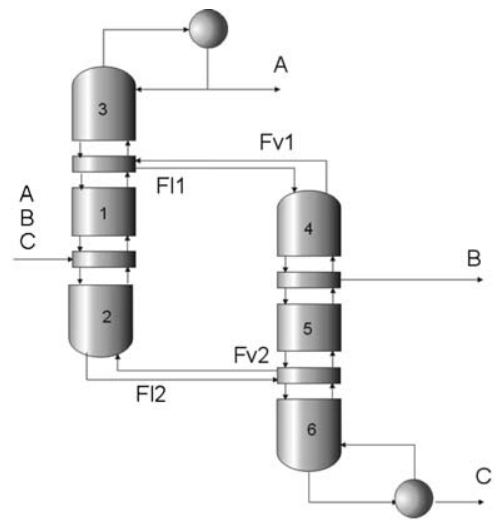

(b)

PU-L

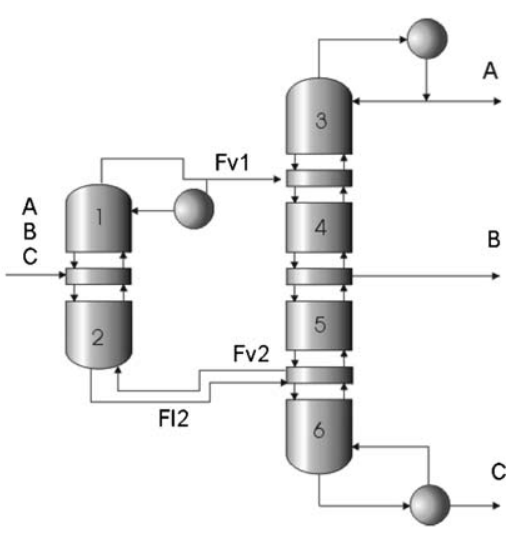

(c)

RV

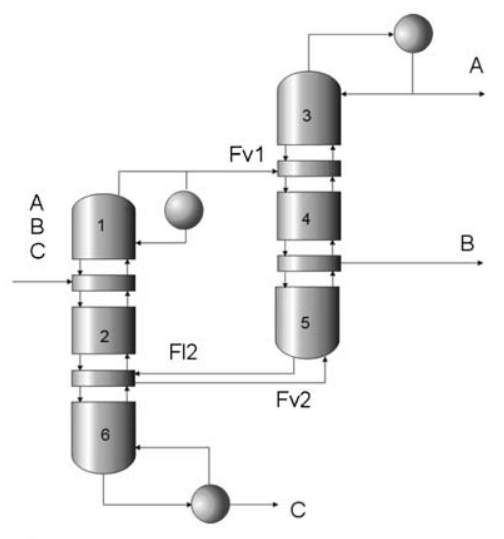

(e)

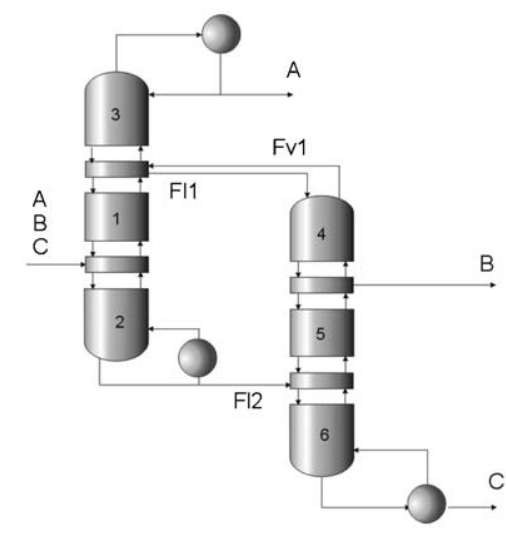

(f)

RL-U

prefractionator must have higher pressure than the main column in order to enter in it. Also, the pressure in the recycled vapour stream from the main column to the bottoms of the prefractionator must be higher than that of the bottoms of the prefractionator. This cannot happen in a natural form. It requires the use of a compressor to modify the pressure of one stream. The problem of the pressure can be avoided by modifying the direction of the interconnecting streams as indicated in the six alternative configurations shown in Fig. 4.

It is important to mention that contributions in the field of exergy analysis have been reported regarding distillation columns. Agrawal and Fidkowski [10] obtained that important savings in total annual costs can be achieved in distillation columns by using intermediate reboilers in the rectifying section and intermediate condensers in the stripping section. Such arrangements let use less expensive utilities in the separation of highly non-ideal mixtures. Rivero [11] and Rivero et al. [12] have presented studies of the simulation of diabatic distillation columns (heat exchangers in all stages) and have reported reduction in exergy loss by diabatization of distillation columns. Koeijer and Rivero [13] have compared the exergy loss in one diabatic experimental distillation column and one adiabatic distillation column. They found that the second law efficiency, in the case of the diabatic distillation column, was increased significantly in contrast to that obtained in the adiabatic distillation column for the separation of a mixture of water/ethanol. Also, the most important conclusion presented was that diabatic distillation columns presented lower exergy loss than adiabatic distillation columns. Jiménez et al. [14] have pointed out the importance of significantly exergy savings by diabatization of distillation columns through the use of heat exchangers in series. They highlighted the importance of the retrofit of the distillation columns that are the largest energy degrading units. 
Those papers are related to single distillation columns; for that reason, the main contribution of this paper is to present an analysis of thermodynamic efficiencies of the alternative schemes to the Petlyuk column shown in Fig. 2c. The Petlyuk distillation column is useful because can be implemented in a single shell reducing both energy and capital costs. Typical energy and capital savings of $30 \%$ are obtained with this column. BASF has implemented this kind of thermally coupled distillation sequence in the industry by using the divided wall distillation column; recently Kaibel and Schoenmakers [2] have reported that BASF has implemented the biggest thermally coupled distillation column in a Fischer-Tropsch plant.

\section{Design and thermodynamic efficiency of the alternate distillation schemes to the Petlyuk column}

The design and optimisation methods for the case of TCDS with side columns (Figs. 2a and b) and the corresponding methods for the Petlyuk column can be found in the works of Hernández and Jiménez $[15,16]$. Briefly, the designs of the TCDS schemes can be obtained from the conventional distillation sequences of Fig. 1 and then optimised for minimum energy consumption through a search using the two recycle streams as search variables. These recycle streams are changed until the minimum consumption of energy in the reboilers is detected. The design and optimisation strategies of the alternative distillation schemes are very similar to those used for the Petlyuk column. For example, sections in the PU-V (Petlyuk with unidirectional flows of vapour, Fig. 4a) can be obtained by moving Section 6 in the main column of the Petlyuk configuration (Fig. 2c) to the bottom of the prefractionator; the PU-L configuration (Petlyuk with unidirectional flows of liquid, Fig. 4b) is obtained when Section 3 of the main column of the Petlyuk scheme (Fig. 2c) is moved to the top of the prefractionator of the Petlyuk configuration. The rest of the alternative distillation schemes to the Petlyuk column are similar but include a reduction in the number of interconnecting streams; the details in the optimisation procedure are available in the work of Jiménez et al. [17].

With the optimised designs of the TCDS schemes, thermodynamic efficiencies can be computed using the laws of thermodynamics. For this task, we used the equations reported by Seader and Henley [18]. The equations are:

First Law of thermodynamics:

$$
\sum_{\text {out of system }}\left(n h+Q+W_{\mathrm{s}}\right)-\sum_{\text {in to system }}\left(n h+Q+W_{\mathrm{s}}\right)=0 .
$$

Second Law of thermodynamics:

$$
\sum_{\text {out of system }}\left(n s+Q / T_{\mathrm{s}}\right)-\sum_{\text {in to system }}\left(n s+Q / T_{\mathrm{s}}\right)=\Delta S_{\text {irr }} .
$$

Exergy balance:

$$
\sum_{\text {in to system }}\left[n b+Q\left(1-\frac{T_{0}}{T_{\mathrm{S}}}\right)+W_{\mathrm{s}}\right]-\sum_{\text {out of system }}\left[n b+Q\left(1-\frac{T_{0}}{T_{\mathrm{S}}}\right)+W_{\mathrm{s}}\right]=\mathrm{LW} .
$$

Minimum work of separation:

$$
W_{\min }=\sum_{\text {out of system }} n b-\sum_{\text {in to system }} n b .
$$

Second Law efficiency:

$$
\eta=\frac{W_{\min }}{\mathrm{LW}+W_{\min }}
$$

where $b=h-T_{0} s$ is the exergy function, $\mathrm{LW}=T_{0} \Delta S_{\text {irr }}$ is the lost work in the system and $\eta$ is the thermodynamic efficiency. Thermodynamic properties like enthalpies and entropies of the streams of the distillation sequences were evaluated through the use of a process simulator, Aspen Plus 11.1 ${ }^{\mathrm{TM}}$. 


\section{Case of study}

We have calculated the second law efficiencies for the Petlyuk column (Fig. 2c) and the six alternate distillations sequences to such a column (Fig. 4) for the separation of a ternary mixture of $n$-pentane (A), $n$-hexane (B) and $n$-heptane (C) with compositions of 40, 20 and $40 \%$ for A, B and C respectively. The alternative distillation sequences include flows in just one direction which, as explained in the works of Agrawal and Fidkowski $[8,9]$, could be useful in their industrial implementation.

\section{Results}

We only present the trends in the optimum energy consumptions and thermodynamic efficiencies in the Petlyuk column and its six alternative distillation schemes. The design and the optimisation results have been previously reported in Jiménez et al. [17].

The energy consumption in the six alternative schemes are very similar to the total heat duty in the Petlyuk column (Table 1). In the cases of the RL and RL-U sequences the total heat duty is $16 \%$ higher than the Petlyuk column. However, in the remaining alternative sequences, energy consumptions are only about $2.5 \%$ superior to that of the Petlyuk column. Hence, the last five designs not only present energy requirements similar to those of the Petlyuk column, but are also expected to be more easily implemented in practice.

The second law efficiencies calculated for the six alternative sequences (Table 2) show similar thermodynamic efficiencies to the Petlyuk column. In the case of the PU-V scheme, it has very interesting properties. It has an energy consumption very similar to that in the Petlyuk column and the highest efficiency of all systems. Therefore, the PU-V scheme can be good candidate to be considered as a thermodynamically equivalent system to the Petlyuk column. On the other hand, the RL-U and RL schemes show the higher total heat duty, in comparison to Petlyuk column, and the worst second law efficiencies.

Table 1

Energy consumptions in the Petlyuk column and alternate distillation schemes

\begin{tabular}{ll}
\hline Distillation sequence & Total heat duty supplied in the reboilers (kWatt) \\
\hline Petlyuk & 604.9 \\
PU-L & 626.3 \\
PU-V & 607.3 \\
RL & 702.4 \\
RV & 607.7 \\
RL-U & 697.5 \\
RV-U & 627.8 \\
\hline
\end{tabular}

Table 2

Thermodynamic efficiencies

\begin{tabular}{ll}
\hline Distillation sequence & $\eta(\%)$ \\
\hline Petlyuk & 31.82 \\
PU-L & 30.57 \\
PU-V & 32.31 \\
RL & 29.24 \\
RV & 31.55 \\
RL-U & 29.16 \\
RV-U & 30.86 \\
\hline
\end{tabular}


In general, the results show that the six alternative schemes to the Petlyuk column have similar energy consumptions and second law efficiencies. For systems where both thermal couplings are preserved, the thermodynamic efficiency is better; however, that is not true for the cases where one reduces the number of interconnections or thermal couplings with respect to the original Petlyuk system.

Finally, it is important to state that the thermodynamic analysis can be extended to other complex distillation sequences with heat integration instead of thermal couplings. For example, in the case of the conventional direct distillation sequence shown in Fig. 1a, the operational pressure of column $\mathrm{C} 1 \mathrm{can}$ be high enough to integrate the heat duty of the condenser in the reboiler of column $\mathrm{C} 2$. This is also called multieffect distillation sequence or forward heat integration. This integrated distillation sequence requires only $416.0 \mathrm{~kW}$ to achieve the separation of the ternary mixture. The heat integrated distillation sequence presents savings around $30 \%$ in contrast to the Petlyuk column, but its second law efficiency is lower than that of the Petlyuk column $(22.4 \%$ vs. $31.82 \%)$. This result can be explained in terms of the higher operational pressure of the column $\mathrm{C} 1$ required to integrate energy in the second column C2 (Fig. 1a). The high operational pressure of the heat integrated distillation columns demands the use of energy at higher level of temperature than that of the Petlyuk column.

\section{Conclusions}

The energy requirements and the second law efficiencies for the separation of a ternary mixture of hydrocarbons for the Petlyuk column and six alternative arrangements to that system were investigated. The results indicate that the alternative distillation systems present very similar values of energy demands in the reboilers and thermodynamic efficiencies. These results are important because allow us to conclude that the energy savings of up to $50 \%$ predicted for the Petlyuk system can be obtained in practice through the industrial implementation of alternative distillation sequences with unidirectional flows, which are thermodynamically identical to the Petlyuk column but with better expected operational behavior.

\section{Acknowledgements}

This research project was supported by PROMEP and Universidad de Guanajuato, México.

\section{References}

[1] Engelien HK, Larsson T, Skogestad S. Implementation of Optimal Operation for Heat Integrated Distillation Columns. Trans Inst Chem Eng 2003;81:277-81.

[2] Kaibel G, Schoenmakers H. Chemical Process Design in Practice. In: Grievink J, Schijndel JV, editors. Proceedings of ESCAPE-12 (Computer Aided Process Engineering, 10), vol. 10. The Hague: Elsevier; 2002. p. 9-14.

[3] Triantafyllou C, Smith R. The Design and Optimisation of Fully Thermally Coupled Distillation Columns. Trans Inst Chem Eng 1992;70:118-32.

[4] Rong BG, Kraslawski A. Optimal Design of Distillation Flowsheets with a Lower Number of Thermal Couplings for Multicomponent Separations. Ind Eng Chem Res 2002;41:5716-26.

[5] Rong BG, Kraslawski A. Partially Thermally Coupled Distillation Systems for Multicomponent Separations. AIChE J 2003; 49:1340-7.

[6] Hernández S, Pereira-Pech S, Jiménez A, Rico-Ramírez V. Energy Efficiency of an Indirect Thermally Coupled Distillation Sequence. The Can J Chem Eng 2003;81:1087-92.

[7] Hernández S, Jiménez A. Design of Energy-Efficient Petlyuk Systems. Comput Chem Eng 1999;23:1005-10.

[8] Agrawal R, Fidkowski Z. More Operable Arrangements of Fully Thermally Coupled Distillation Columns. AIChE J 1998;44:2565-8.

[9] Agrawal R, Fidkowski Z. New Thermally Coupled Schemes for Ternary Distillation. AIChE J 1999;45:485-96.

[10] Agrawal R, Fidkowski ZT. On the Use of Intermediate Reboilers in the Rectifying Section and Condensers in the Stripping Section of a Distillation Column. Ind Eng Chem Res 1996;35(8):2801-7.

[11] Rivero R. Exergy Simulation and Optimization of Adiabatic and Diabatic Binary Distillation. Energy 2001;26(6):561-93.

[12] Rivero R, García M, Urquiza J. Simulation, Exergy Analysis and Application of Diabatic Distillation to a Tertiary Amyl Methyl Ether Production Unit of a Crude Oil Refinery. Energy 2004;29(3):467-89.

[13] De Koeijer GM, Rivero R. Entropy Production and Exergy Loss in Experimental Distillation Columns. Chemical Engineering Science 2003;58(8):1587-97. 
[14] Jiménez ES, Salomon P, Rivero R, Rendon C, Hoffmann KH, Schaller M, et al. Optimization of a Diabatic Distillation Column with Sequential Heat Exchangers. Ind Eng Chem Res 2004;43(23):7566-71.

[15] Hernández S, Jiménez A. Design of Optimal Thermally Coupled Distillation Systems Using a Dynamic Model. Trans Inst Chem Eng 1996;74:357-62.

[16] Hernández S, Jiménez A. Controllability Analysis of Thermally Coupled Distillation Systems. Ind Eng Chem Res 1999;38:3957-63.

[17] Jiménez A, Ramírez N, Castro A, Hernández S. Design and Energy Performance of Alternative Schemes to the Petlyuk Distillation System. Trans Inst Chem Eng 2003;81:518-24.

[18] Seader JD, Henley E. Separation Process Principles. USA: Wiley; 1998. 